http://dx.doi.org/10.12795/PH.1990.v05.i01.13

\title{
Interrelación lexemático-sintáctica de la unidad lingüística parecer en una actuación concreta: habla urbana culta de Sevilla
}

Rosario Guillén Sutil

\section{Introducción}

En este trabajo, partimos de un básico análisis de la unidad linguiística parecer en relación a su sistema funcional idealizado. Este sistema funcional nos va a servir como modelo de relaciones con vistas al estudio del comportamiento discursivo de dicha unidad, en el nivel culto del Habla Urbana de Sevilla ${ }^{l}$.

Así, con un criterio lingüístico, consideraremos, en primer lugar, el dinamismo sistémico de la unidad antes mencionada, situándonos, pues, en un nivel de abstracción donde observaremos su funcionamiento ideal en la lengua. Se parte, por tanto, de la postura comúnmente aceptada de que el objetivo del investigador no se limita sólo a la descripción exhaustiva del corpus, sino que su meta final es describir el sistema subyacente que rige la lengua, partiendo de los datos iniciales que le proporciona aquél. De tal manera, como señala el profesor V. Lamiquiz, «nuestra observación investigadora se centra en la producción sistemática de la lengua española. Y una vez dilucidadas las posibilidades de la operatividad idealizada señalamos la selección realizada o posibilidad elegida por el grupo de sevillanos cultos, en sus diversos estratos de generación y sexo, como un específico comportamiento que conlleva un

${ }^{1}$ El corpus utilizado es el de las encuestas del Habla Urbana de Sevilla - nivel culto, publicadas en Sociolingüística Andaluza 2. (Sevilla: P. Universidad de Sevilla, 1983). Cfr. también nuestra Tesis Doctoral (inédita): La expresión de la opinión subjetiva en el comportamiento discursivo del Habla Urbana de Sevilla. (Universidad de Sevilla, 1988), para aclarar ésta y otras cuestiones teóricas. 
simbolismo social reveladon ${ }^{2}$. Iniciamos, pues, la investigación desde una perspectiva lingüística y nos dirigimos, en consecuencia, hacia la sociolingüística ${ }^{3}$.

Para el análisis lingüístico, nos basamos en un método idóneo de estudio, el llamado «módulo» o modelo teórico lingüístico que L.V. Bertalanffy define así: «un ejemplar o modelo teórico es una construcción conceptual formalizada que refleja clara y esquemáticamente ciertos aspectos de un fenómeno natural y que permite hacer deducciones y predicciones comprobables» ${ }^{4}$.

Una vez recopilados y acumulados los hechos observados, hemos pretendido ordenarlos de forma coherente y sistemática, para luego plasmarlos en un módulo que, siguiendo el método de V. Lamiquiz, lo definimos como «un programa automático para el futuro uso discursivo. Corresponde a una simulación abstracta (...) en hipótesis generativa. Incluye toda la carga de operatividad funcional necesaria para la génesis deductiva de la serie de manifestaciones discursivas posibles»5.

El modelo se expresa por medio de una fórmula general o por medio de un diagrama o esquema gráfico, en el que pretendemos reunir todos los requisitos funcionales necesarios de la unidad parecer. En él señalamos la interrelación que existe entre componentes lexemáticos -con sus marcas significativas y unidades con que alterna- y componentes sintácticos como funtor de predicación ${ }^{6}$, predisposiciones actanciales obligadas, y condicionamientos de construcción. En esta relación mutua, observamos que cada valor lexemático del verbo que consideramos, tiene una determinada construcción sintáctica y que, a la inversa, cada construcción sintáctica nos dará el correspondiente valor lexemático.

Vistas las cosas así, la muestra que se logre mediante este análisis, nos servirá de interesante material comparativo y deductivo con respecto al módulo de uso discursivo del verbo parecer en el Habla Urbana Culta de Sevilla, y de punto de referencia a la hora de organizar unas leyes veraces que muestren el uso actualizado de los hablantes sevillanos en sus variantes y coincidencias con respecto al módulo virtual. Este se encuentra en contraposición complementaria con el discursivo, pues muestra las alternativas ideales de este último, y las acepciones que el Diccionrio da para dicho verbo.

2 V. Lamiquiz, «El discurso sociolingüístico: la producción posible y el producto actualizado», Sociolingüística Andaluza 3.: El discurso sociolingüístico (Sevilla: P. Universidad de Sevilla, 1985), p. 14.

${ }^{3}$ Desde un punto de vista sociolingüístico la unidad parecer resulta interesante de estudiar, debido a que su frecuencia de empleo discursivo en el Habla Urbana Culta de Sevilla es bastante elevada. En concreto, la unidad parecer se localiza entre los catorce primeros verbos de mayor frecuencia de uso en estos hablantes, así como por mostrar variedades en sus usos discursivos, según la generación y el sexo.

${ }^{4}$ L.V. Bertalanffy, Perspectivas en la teoría general de sistemas, $2^{\mathrm{a}} \mathrm{ed}$. (Madrid: Alianza-Universidad, 1982), p. 95.

${ }^{5}$ V. Lamiquiz, El contenido lingüístico. Del sistema al discurso (Barcelona: Ariel, 1985), p. 184.

Para la elaboración de los módulos, hemos seguido el método del profesor V. Lamiquiz que los ha ( 'udiado y desarrollado en el libro aquí citado.

${ }^{6}$ Idem, pp 173 y 174.

${ }^{7}$ Real Academia Española, Diccionario de la lengua española, 20" ed. 2v. (Madrid: 1984). 
Para tal investigación, hemos revisado el Diccionario de la Real Academia española y el Diccionario de uso de $\mathrm{M}^{\mathrm{a}}$ Moliner ${ }^{8}$. De ellos se han seleccionado los valores denotativos más básicos que ofrece el sistema de la lengua española a esta unidad; y ambas obras nos muestran las distintas alternativas lexemáticas de ella.

El módulo, como se ha dicho, se completa también dando cuenta de los distintos grupos actanciales que refiere cada valor (acepción) léxico. En cada actante obligado se señala el argumento 9 que llena textualmente el caso que corresponde a una función sintáctica discursiva, y los condicionamientos de construcción sintáctica que requiere cada valor lexemático. Cada uno de los valores de parecer se plasman en ejemplos textuales concretos.

En definitiva, un diagrama lingüístico está constituido por:

$\left.1^{\circ}\right)$ Zona lexemática.

$\left.2^{\circ}\right)$ Sintaxis.

3) Construcción.

$\left.4^{9}\right)$ Ejemplos textuales.

donde tratamos de precisar lo más coherente posible, una descripción que se aproxime a la realidad sincrónica de funcionamiento lingüístico más habitual y actualizada de este verbo.

Así pues, en el modelo queda precisado, en verticalidad, el paradigma de los valores posibles del término y, en horizontalidad, las sucesivas operaciones necesarias para el funcionamiento de cada una de las posibilidades, aší como su sintagmatismo ${ }^{10}$.

${ }^{8} \mathrm{M}^{\mathrm{B}}$ Moliner, Diccionario de uso del español (Madrid: Gredos, 1979).

${ }^{9}$ Según C. Kirschner, la semántica generativa llama a las frases nominales de la estructura profunda argumentos, y a los verbos de dicha estructura, predicados. Cfr. C. Kirschner, Estudios de semántica generativa del español (Salamanca: Almar, 1981), p. 31.

${ }^{10}$ V. Lamiquiz, El contenido... op, cit., p. 174. 


\begin{tabular}{|c|c|c|c|c|}
\hline LEXEMÁTICA & SINTAXIS & \multicolumn{2}{|c|}{ CONSTRUCCIÓN } & EJEMPLOS \\
\hline Alterna con & Actantes & Sintagma & Tipo & \\
\hline Aparentar & Nominativo ( \pm animado) & \multirow[b]{2}{*}{$\begin{array}{l}\text { Verbal } \\
\text { Homogéneo }\end{array}$} & Atributivo & $\begin{array}{l}\text { 1a) } \\
\text { 1b) }\end{array}$ \\
\hline Asemejarse & Doble Nominativo ( \pm animado) & & $\begin{array}{l}\text { Pronominal } \\
\text { recíproco }\end{array}$ & $\begin{array}{l}2 \mathrm{a}) \\
2 \mathrm{~b})\end{array}$ \\
\hline $\begin{array}{l}\text { Creer } \\
\text { Pensar } \\
\text { Opinar } \\
\text { Reprochar } \\
\text { Figurarse }\end{array}$ & $\begin{array}{l}\text { Nominativo (- animado) } \\
\text { Dativo (+ animado) }\end{array}$ & \multirow[t]{3}{*}{$\begin{array}{c}\text { Verbal } \\
\text { Heterogéneo }\end{array}$} & $\begin{array}{l}\text { Atributivo } \\
\text { nexo que + Orac. }\end{array}$ & $\begin{array}{l}3 a) \\
3 b) \\
3 c)\end{array}$ \\
\hline \multirow[t]{2}{*}{$\begin{array}{l}\text { Tener o dar la } \\
\text { impresión }\end{array}$} & \multirow[t]{2}{*}{ Los del verbo Predicativo } & & $\begin{array}{l}\text { Infinitivo } \\
\text { (mismo sujeto) }\end{array}$ & 6a) \\
\hline & & & $\begin{array}{c}\text { Como si } \\
\text { Como que } \\
\text { que + Oración }\end{array}$ & $\begin{array}{l}6 b) \\
6 c) \\
6 d)\end{array}$ \\
\hline
\end{tabular}




\section{Ejemplos textuales}

/1/a. Juan parece inteligente

$/ 1 /$ b. Estos zapatos parecen grandes pata tí

2/a. María se parece a su padre

/2/b. Sevilla se parece a una ciudad encantada

13/a. Nos parece que te equivocas

/3/b. ¿Te parece que la película es interesante?

/3/c. Me parece que no debemos movernos de aquí

14/ Me parece que no has hecho bien

15/a. Me parece que ya no viene

$15 / \mathrm{b}$. ¿Os parece que Luis pueda tener 20 años?

16/a. Juan parecía conocer los procedimientos

/6/b. Parece que Antonio no está enterado del asunto

$/ 6 /$ c. Parecía como si alguien hubiera llamado a la puerta

/6/d. Parecía como que todo se había acabado 


\subsection{Valores sémicos integrados en la unidad PARECER}

Recordamos que para llegar a esta selección de opciones, partimos de los diccionarios antes mencionados.

Según el D.R.A.E., parecer significa, en primer lugar, «aparecer o dejarse ver alguna cosa», seguido de otras acepciones como:

2. «Opinar», «creer».

3. «Hallarse o encontrarse lo que se tenía por perdido».

4. «Tener determinada apariencia o aspecto».

5. «Tener semejanza 0 asemejarse» ${ }^{11}$.

El Diccionario de uso de $\mathrm{M}^{\mathrm{a}}$ Moliner ${ }^{12}$ recoge estas mismas acepciones y algunas otras más que nosotros no hemos considerado; pues, como ya se dijo en otra ocasión, hemos utilizado estos diccionarios como puntos básicos de referencia, de los cuales no se han incluido todas las acepciones que registran diversas obras, sino únicamente las que consideramos que pertenecen a la competencia lingüística de todos los hablantes del español estándar en la actual sincronía.

No hemos considerado, por ejemplo, la primera y tercera acepción del D.R.A.E. porque su uso es poco normal, o el caso de la acepción: parecer bien o mal que estos diccionarios la registran como frase hecha; así como otras acepciones que no hemos creído pertinente para nuestro objetivo investigador.

Debemos hacer saber que se ha considerado como una misma unidad lexemática las formas parecer y parecerse. El D.R.A.E. no las distingue, sino que las toma como una misma entrada léxica, aunque sí señala cuándo esta última forma es pronominal. $\mathrm{M}^{\mathrm{a}}$ Moliner, sin embargo, las considera distintas entradas, y como acepción de la entrada «parecerse» propone, en primer lugar, «asemejarse» donde dice textualmente: «semejarse» (con referencia a persona el único verbo usual es parecerse $a$, en), como en: El italiano y el español se parecen ${ }^{13}$. Así, lo que $\mathrm{M}^{\mathrm{a}}$ Moliner registra como unidad léxica diferente a parecer, el Diccionario de la Academia la introduce como una acepción más de ésta. Ante estas dos posturas, nosotros hemos optado por la segunda. Esto es: considerar a parecerse como una acepción más de la unidad lexemática parecer, siendo su valor el de «asemejarse».

El módulo virtual presenta en su zona lexemática, la variedad de cuatro posibles acepciones. En la primera acepción, parecer ofrece el valor de «aparentar» que, según el $D . R . A . E$., significa «tener determinada apariencia o aspecto» ${ }^{14}$. En la segunda acepción presenta el valor de «asemejarse». Este coincide, pues, con la quinta acepción de dicho diccionario. En la tercera acepción, recogemos los valores: «creer», «opinar»,

${ }^{11}$ Real Academia Española, Diccionario... op. cit., p. 1013.

${ }^{12} \mathrm{M}^{\mathrm{a}}$ Moliner, op. cit., p. 640.

${ }^{13}$ Idem, pp. 640 y 641.

${ }^{14}$ Cfr. nota (11). 
«figurarse» y «reprochan». Los de «creer» y «opinar» están registrados por ambas obras, y los de «reprochar» y «figurarse» sólo los registra $\mathrm{M}^{\mathrm{a}}$ Moliner ${ }^{15}$. Y en la cuarta acepción, parecer tiene el valor de «tener o dar la impresión», documentada también en el diccionario de $\mathrm{M}^{\mathrm{a}}$ Moliner.

Como se dijo anteriormente, este primer paso para la confección del módulo, no se ha hecho ignorando las necesidades actanciales y combinatorias de cada valor de parecer. Mas aún, todos y cada uno de los apartados del modelo se determinan mutuamente. En este sentido, coincidimos con el profesor G. Wotjak cuando dice que la determinación de la cantidad de variantes sigue siendo una de sus mayores preocupaciones, puesto que aún faltan criterios teóricos exactos. Lo que parece evidente es que «el criterio diferencial semántico siempre será subjetivo y que no pueden determinarse las variantes si no se basan, por ejemplo, en un detallado análisis componencial semántico del propio verbo y de la caracterización semántico denotativa - referencial y funcional de sus actantes» ${ }^{16}$.

\subsection{Tipología sintáctica}

Como dicen las gramáticas, parecer es un verbo de los llamado seudocopulati$v o$, y cuando en una oración funciona como tal «denota el atributo de la proposición indicando justamente el número y persona del sujeto y el tiempo del mismo atributo» ${ }^{17}$. Así, parecer puede funcionar como verbo atributivo, cuyo atributo, ya sea adjetivo o sustantivo, modifica al sujeto y concuerda con él en género y número.

Pero parecer también puede funcionar en el discurso como verbo intransitivo, y así se presenta cuando ofrece la forma pronominal recíproca ${ }^{18}$.

${ }^{15} \mathrm{M}^{\mathrm{a}}$ Moliner especifica que parecer se emplea frecuentemente para atenuar un juicio, una aventura o un reproche: «Me parece que no has hecho bien». op. cit., p. 640.

${ }^{16} \mathrm{G}$. Wotyak, «Acerca de la confección de un diccionario de valencias de verbos españoles», R.P.H., XVIII, (Heftz, 1979) p. 310.

${ }^{17}$ A. Bello, Gramática de la lengua española (Madrid: Edaf, 1982), p. 43.

${ }^{18}$ Las construcciones con se, como supone M. C. Bobes, presentan en español una variedad y frecuencia considerables. «Constituyen uno de los casos más complejos cuando se trata de realizar análisis sintácticos, ya que el valor, la función y el contenido del se es, en ocasiones, difícil de precisar». M. C. Bobes: «Construcciones castellanas con SE», Revista Española de Lingüística, 41, 1, (1974), p. 87.

Por lo que a nosotros nos concierne, nos interesamos en estudiar el funcionamiento del se cuando se incorpora a un lexema verbal como es el caso de parecer. El valor que toma el se al construirse con un verbo como tal es el de recíproco. Así, parecer además de funcionar como verbo atributivo, se le presenta también la posibilidad de funcionar como pronominal recíproco, presentando, pues, una estructura intransitiva. La reciprocidad se la da el pronombre átono de tercera persona se cuando se añade al verbo. Este pasaría entonces a la forma parecerse. Debemos decir, no obstante, que en nuestro análisis, el verbo parecer por su contenido semántico, no es un verbo recíproco, pero, como se ha dicho, adquiere el carácter de reciprocidad cuando en la oración con la que se construye, se le añade el mencionado pronombre, pasando, pues, a la forma parecerse, tomada por nosotros como un posible valor del lexema verbal parecer, este valor será, por tanto, el de «asemejarse». 


\subsubsection{Estructuras actanciales}

En este apartado del módulo estudiaremos los actantes exigidos por cada uno de los valores que requiere la unidad parecer ${ }^{19}$.

Parecer con el valor de «aparentan que indica «manifestar o dar a entender lo que no es o no hay» ${ }^{20}$, exige el uso de un actante nominativo ${ }^{21}$. Este está recubierto nominalmente por un argumento cuyo rasgo es ( \pm animado). Por ejemplo:

/1/a. Juan parece inteligente.

$/ 1 / b$. Estos zapatos parecen grandes para tí.

En /1/a. el sujeto está visto como (+ animado), ya que se trata de un sustantivo que hace referencia a una persona (Juan). Mientras que en $/ 1 / \mathrm{b}$. es (- animado) pues el sujeto al que hace referencia ahora el verbo, es una cosa (estos zapatos). Por tanto, parecer con el mencionado valor, sólo exige con carácter de obligatoriedad, la presencia única y exclusiva de un actante en la perspectiva de una producción discursiva concreta. Sin embargo, parecer en las demás acepciones del módulo y con otros posibles valores, se caracteriza por llevar dos actantes obligados como es el caso de la segunda y tercera acepción del módulo ideal pues en la cuarta no lleva ninguno, ya que con el valor de «tener o dar la impresión» parecer funciona como verbo auxiliar y los posibles actantes que se puedan dar son del verbo auxiliado.

Con el valor de «asemejarse» (tener parecido con otra persona o cosa), los actantes obligados son doble nominativo. El nominativo, según la teoría de B. Pottier, es el actante del no acontecimiento puesto que no tiene diferencia de potencial. Ejemplos textuales:

12/a. María se parece a su padre.

$/ 2 / \mathrm{b}$. Sevilla se parece a una ciudad encantada.

En /2/a. y /2/b. se instala el nominativo conceptual. Es decir, se instala tanto en María como su padre o Sevilla y una ciudad encantada. Ambos elementos sujeto (María) objeto (su padre) se identifican en una referencia. Hay, pues, corresponden-

${ }^{19}$ A pesar de los numerosos trabajos que se han hecho acerca de la teoría de los casos y de los actantes, no existe aún un sistema casual completo que podamos aceptar de manera universal y definitiva para todas las lenguas, ya que existen diferentes teorías desde una u otra perspectiva que han sufrido algunas transformaciones (como, por ejemplo, la teoría de Ch. Fillmore «The case for case», Universals in Linguistic Theory. Ed. by Bach and R. T. Harmes. N. York, Renchard, 1968) y que puede que sufran algunas más. En este trabajo hablaremos de actantes según el criterio seguido por B. Pottier («Theory des cas: logique et linguistique», Modeles logiques et niveaux d'analyse linguistique $\mathrm{Metz}$, Centre d'analyse syntaxique de l'Université, 1974). Por tanto, entendemos por actancias las funciones sintácticas exigidas por cada funtor de predicación y los elementos nominales o argumentos que las actualizan en el discurso. Es un concepto relacionado con el caso, aunque no se pueden considerar completamente equivalentes.

${ }^{20}$ Definición recogida por el DRAE, op. cit., p. 100.

${ }^{21} \mathrm{Al}$ ser parecer un verbo que indica percepción mental, generalmente se realiza sin esfuerzo por parte del hablante. Al tener esta indicación obliga el uso de un actante nominativo. 
cia referencial del sujeto con el objeto, pues la correspondencia de un objeto con su sujeto, tanto en el nivel léxico como en el gramatical, supone su identidad referencial no su identidad funcional ${ }^{22}$. Así, distintas funciones lingüísticas pueden representar un mismo caso conceptual.

El doble nominativo está situado en la zona anterior de potencia positiva ${ }^{23}$, ya que no cabe aquí el no acontecimiento con diferencia de potencial, puesto que el proceso activo y pasivo se dan simultáneamente.

$\mathrm{El}$ argumento que recubre nominalmente a este doble nominativo está marcado también por el rasgo ( \pm animado), pues tanto el agente como el paciente, que se dan simultáneamente, pueden ser referidos a persona o cosa, como así se refleja en /2/a. y $/ 2 / \mathrm{b}$.

En cuanto a los valores de la tercera acepción exigen también la presencia de dos actantes. En este caso son: el nominativo y el dativo. El actante nominativo lo recubre un grupo sintagmático introducido por el transpositor que cuya función es la de atributo, y como se trata de una atribución a través de una subordinada oracional, la marca condicionante es (- animado).

Además del actante nominativo que, como se ha dicho anteriormente, pertenece a la zona central primaria, estos valores necesitan la presencia de un actante de la zona posterior de potencia negativa como es el dativo, cuyo argumento es llenado con el rasgo (+ animado). Ejemplos textuales:

/3/a. Nos parece que te equivocas.

$/ 3 / \mathrm{b}$. ¿Te parece que la película es interesante?

/3/c. Me parece que no debemos movernos de aquí.

14/ Me parece que no has hecho bien.

15/a. Me parece que ya no viene.

$15 / \mathrm{b}$. ¿Os parece que Luis pueda tener 20 años?

El rasgo (+ animado) es debido a que el dativo -que no recibe la acción directa del verbo- es un pronombre personal átono que sustituye a la persona hablante.

El actante dativo en forma de pronombre personal, es obligado por el verbo cuando éste en una oración toma el valor de «opinar», pues de no ser así, es decir, de no llevar el pronombre, la oración que resulta no expresaría la opinión subjetiva del sujeto hablante.

En la cuarta acepción del diagrama, parecer ofrece el valor de «tener o dar la impresión». En esta ocasión, se presenta un rasgo actancial muy curioso debido a que tal verbo no es el núcleo de la oración, sino que su función es la de verbo auxiliar. Por ello, los actantes exigidos no serán los de parecer, sino los del verbo predicativo. Este incide funcionalmente sobre parecer, pues la predicación de éste es nula. Su función es la de verbo auxiliar del predicado.

${ }^{22}$ B. García Hernández, «Gramática de los casos y complementariedad léxica» R.S.E.L, 17, 1 (1987), p. 8.

${ }^{23}$ Cfr. B. Pottier, op, cit., p. 132. 
En los ejemplos:

/6/a. El niño parecía saber mucho.

$/ 6 /$ b. Juan parecía conocer los procedimientos.

el /6/a. admite la transformación:

«El niño, al parecer, sabía mucho»

donde parecer se convierte en una expresión adverbial, y los actantes nominativo (el niño) y acusativo (mucho) son exigidos por el verbo auxiliado saber. Y la /6/b. se transforma en:

«Juan, al parecer, conocía los procedimientos».

Así pues, no es el verbo parecer el que induce los actantes, sino el verbo principal, pues aunque en estas dos oraciones transformadas se suprima parecer, no hay ningún cambio en la selección de los actantes. Además, tampoco podrían ser de parecer porque el objeto que forma el segundo actante en /6/a. y /6/b. tiene la función de implemento, y al ser parecer un verbo funcionalmente atributivo o intransitivo no podría llevar este tipo de complementación.

\subsubsection{Construcción sintáctica}

Como acabamos de decir, parecer es uno de los verbos que ha quedado permanentemente ceñido a la estructura de verbo funcionalmente atributivo e intransitivo. Al presentar tales estructuras no puede ser complementado sémicamente por un objeto en función de implemento ${ }^{24}$, sino mediante otro tipo de complementación que es el que vamos a estudiar a continuación.

\subsubsection{Construcción del primer valor de PARECER: «aparentar»}

El esquema estructural que corresponde a este valor será:

$$
\mathrm{SN} 1+\mathrm{V}+\text { atributo }
$$

${ }^{24}$ Seguimos la terminología de E. Alarcos, «Verbo transitivo, verbo intransitivo y estructura del predicado», Estudios de gramática funcional del español. 3². ed. (Madrid: Gredos, 1984). 
como en:

/1/a. Juan parece inteligente.

$/ 1 / \mathrm{b}$. Estos zapatos parecen grandes para tr.

El verbo parecer presenta en estos casos una estructura atributiva (forma de predicación con unos verbos determinados: ser, estar, parecer, etc.) Estos están desemantizados y acompañados de un sintagma complementario atributo que modifica directamente al sujeto, pues, como dice C. Hernández, la relación semántica que puede haber entre sujeto y atributo es más estricta que entre sujeto e implemento ${ }^{25}$. Por consiguiente, la unidad parecer con este tipo de construcción sintáctica, funciona como verbo atributivo, pues, como bien se sabe, y así lo reflejan J. Alcina y J. M. Blecua, «se produce la integración por medio del pronombre personal átono /lo/ que con esta única forma alude al nombre sustantivo o adjetivo independientemente de su género y número» ${ }^{26}$. Por ejemplo:

/1/a. Juan parece inteligente...... lo parece.

$/ 1 / \mathrm{b}$. Estos zapatos parecen grandes para tí...... lo parecen.

La categoría de atributo la puede llevar también un sustantivo ya que tiene la misma relación con el sujeto que cualquier adjetivo:

/1/c. Juan parece el ministro de Hacienda lo parece.

En este caso, el verbo parecer forma una estructura analítica paralela a las transitivas, pero el atributo modifica más directamente a su sujeto que el implemento.

Así, en las oraciones /1/a. y /1/b. no existe, por tanto, diferencia de construcción. La diferencia que puede haber entre una y otra oración está en el rasgo que llena el argumento de sujeto funcional. En /1/a. el sujeto es Juan (persona) y en /1/b. estos zapatos (cosa).

Normalmente, y así se refleja, la oración /1/b. se puede construir con un complemento de persona: «estos zapatos parecen grandes para tí», pero este complemento de persona no es un participante obligado por el verbo, sino que su participación es facultativa.

En definitiva, consideramos a parecer, con el valor antes mencionado, como verbo funcionalmente atributivo, y esta atribución constituye el rasgo sintáctico que señala el valor del mismo. Ahora bien, también influye en la significación de «tener determinada apariencia o aspecto», el hecho de actuar parecer sólo en la oración. Es

${ }^{25}$ C. Hernández, Gramática funcional del español (Madrid: Gredos, 1984), p. 73.

${ }^{26}$ J. Alcina y J. M. Blecua, Gramática española, 4" ed. (Barcelona: Ariel, 1983), p. 858. 
decir, se construye como un sintagma verbal homogéneo ${ }^{27}$. Su predicación es completa, ya que no necesita de otro elemento verbal para completar su significado. Este es, pues, autónomo.

\subsubsection{Construcción del segundo valor de PARECER: "asemejarse"}

La construcción que requiere ahora parecer para significar «tener semejanza o asemejarse» es la pronominal recíproca, y el esquema estructural que presenta es el que sigue:

$$
\mathrm{SN} 1+\mathrm{V}+\mathrm{a}+\mathrm{SN} 2
$$

Su función no es ahora atributiva, sino intransitiva. Ejemplos textuales:

12/a. María se parece a su padre.

$/ 2 / \mathrm{b}$. Sevilla se parece a una ciudad encantada.

Los grupos sintagmáticos a su padre y a una ciudad encantada funcionan de complemento.

La construcción /2/a. y /2/b. se considera recíproca porque en una oración como tal, dos sujetos intercambian una misma acción de la que participan a la vez como sujeto y como objeto. La estructura que presenta sería:

$$
\mathrm{SN} 1+\mathrm{V}+\mathrm{SN} 2 \ldots . . . \mathrm{SN} 2+\mathrm{V}+\mathrm{SN} 1
$$

María se parece a su padre...... su padre se parece a María.

Sevilla se parece a una ciudad encantada...... una ciudad encantada se parece a Sevilla.

En este par de oraciones, el sujeto y el objeto son intercambiables. El proceso activo y pasivo se dan simultáneamente, y al tratarse de dos procesos paralelos la

${ }^{27}$ Es necesario subrayar -a propósito de los sintagmas verbales homogéneos y heterogéneos- que desde una perspectiva morfosintáctica, cuando el hablante utiliza una expresión del tipo Me parece que Juan ya no viene, la comunica una oración que a pesar de llevar dos formas verbales, tiene un solo significado. Esto es: al estar construida la oración con dos verbos y llevando un mismo contenido semántico (en este caso es el de opinión), hemos creído necesario hacer una distinción en este tipo de sintagma verbal. Por ello, considerando la terminología de V. Lamiquiz (Lengua española. Métodos y estructuras lingüísticas, (Barcelona: Ariel, 1987), p. 159), llamamos sintagma verbal heterogéneo al que conlleva dos núcleos verbales (me parece que Juan ya no viene), aunque cada verbo tenga también sus propias características formales, semánticas y distintos actantes. De igual modo, consideramos el sintagma verbal heterogéneo cuando al verbo principal le acompaña un infinitivo, como por ejemplo Juan parecía conocer los procedimientos. Como en el caso anterior, a pesar de que la oración se expresa con dos verbos, ambos mantienen un contenido propio. Por otro lado, cuando parecer actúa por sí solo en un discurso dado, lo denominamos sintagma verbal homogéneo. Su predicación es completa, ya que no necesita de otro elemento verbal para completar su significado, como por ejemplo Juan parece un buen muchado. Su significado es autónomo, diferenciándose así del heterogéneo (dos verbos y un sólo significado). 
«diátesis recíproca, como dice L. Tesnière ${ }^{28}$, está siempre en plural, como en: María y su padre se parecen, Sevilla y una ciudad encantada se parecen.

Coincidimos con I. Bosque y A. Borillo ${ }^{29}$ en el hecho de que parecer con este tipo de construcción, sea un verbo simétrico, pues para que un predicado sea simétrico tiene que admitir el sintagma el uno al otro y el sintagma entre sí, como así se refleja en: María y su padre se parecen el uno al otro, Sevilla y una ciudad encantada se parecen la una a la otra, y también cabe se parecen entre sí.

$\mathrm{Su}$ construcción como SV homogéneo es otro rasgo de la significación de «asemejarse». Valor que hace que este verbo presente una estructura intransitiva.

\subsubsection{Construcción del tercer valor de PARECER: «opinar»}

Parecer vuelve de nuevo a construirse como verbo atributivo, siendo su esquema estructural el siguiente:

$$
\text { Pr. }+ \text { V + que }+ \text { Or. }
$$

Ejemplos textuales:

/3/a. Nos parece que te equivocas.

$13 /$ b. ¿Te parece que la película es muy interesante?

$/ 3 / \mathrm{c}$. Me parece que no debemos movernos de aquí.

14\% Me parece que no has hecho bien.

/5/a. Me parece que ya no viene.

$/ 5 / \mathrm{b}$. ¿Os parece que Luis pueda tener 20 años?

Tenemos, pues, que parecer con el valor arriba expuesto, se construye con una oración subordinada introducida por el transpositor que.

Con respecto a este tipo de estructura, nos encontramos con que no todos los gramáticos coinciden en la función que puede tener la oración subordinada a parecer. Para unos funcionaría de $s u j e t^{30}$, y para otros su función sería la de atributo ${ }^{31}$. Bajo nuestro punto de vista, la mencionada oración subordinada aparece en posición de atributo de parecer, ya que el sintagma oracional que acompaña a éste funciona como cualquier sustantivo, y como tal sustantivo cuando se construye con un tipo de verbos como ser, estar o parecer ofrece las características funcionales que ello requiere. No obstante, se podría pensar que esta caracterización no es suficiente para decir que tal

${ }^{28}$ L. Tesnière, Eléments de syntaxe structurale. $2^{2}$. ed. (Paris: Klinckisieck, 1976, p. 156.

${ }^{29}$ I. Bosque, Sobre la negación (Madrid: Cátedra, 1980)- A. Borillo, «Remarques sur les verbes symétriques francais», Langue Francaise. 11 (1971),

${ }^{30}$ Entre otros, MP Moliner, op. cit. y J. Alcina y J. M. Blecua, op. cit..

${ }^{31}$ Entre otros, S. Gutiérrez, Variaciones sobre la atribución (Universidad de León: Colección contexto, 1986), -E. Alarcos, op. cit.. 
oración sustantivada puede funcionar de atributo, puesto que parecer, en este caso, no lleva ningún sujeto léxico explícito al que se le pueda atribuir dicha oración. Por nuestra parte, hablamos, como también lo habla E. Alarcos ${ }^{32}$, de sujeto gramatical implícito en el morfema del verbo y también de ese sujeto implícito pronominal como es el caso del francés «Ill» o del antiguo «Illud» (eso) latino.

Vistas las cosas así, los atributos nominales de las oraciones /3/a., /3/b., /3/c., / 4/, /5/a. y /5/b. pueden ser perfectamente conmutables por el pronombre átono /lo/, puesto que éste tiene, en tales casos, un valor neutro independiente ${ }^{33}$.

Creemos también que su función de sujeto no es la correcta por el hecho de que su sustitución pronominal nunca se da en un pronombre personal tónico propio de sujeto (yo, tú, él, etc.).

Una característica más a favor de la atribución de las oraciones subordinadas a parecer, es que pueden ser sustituidas por el adverbio así, fenómeno que, al parecer, sólo sucede en la atribución, por ejemplo:

/3/a. Nos parece que te equivocas.... lo parece / así parece.

/3/b. ¿Te parece que la película es interesante?.... lo parece / así parece

/3/c. Me parece que no debemos movernos de aquí.... lo parece/ así parece etc.

Además de todo lo expuesto, observamos que si un tipo de oración como: me parece que la película es interesante (respuesta de la $/ 3 / \mathrm{b}$.) anteponemos el sujeto de la subordinada a la principal, como $\mathrm{en}^{34}$ : la película me parece interesante, no significa que con esta anteposición haya habido un cambio de función sintáctica, pues película sigue siendo el sujeto de es. Esto se debe a que al cambiar los morfemas finales del sustantivo película y de la forma verbal es, ya no concuerda dicho sustantivo con el verbo parecer, como en:

«Me parece que las películas son interesantes» «Las películas parece que son interesantes.

Mientras que esta otra resultaría con una concordancia agramatical: «las películas parecen que son interesantes»

Una característica esencial de los sujetos de las oraciones españolas es que concuerdan en número y persona con un verbo del predicado y en género y número con el atributo (adj. sust.) de las oraciones copulativas.

La anteposición no es algo exclusivo de la función sintáctica. El cambio de orden no altera, pues, la organización sintagmática, sino que obedece a la función pragmática de tematización.

Así pues, cuando el hablante del español estándar elige el verbo parecer para expresar una cierta opinión, el valor lexemático que toma éste, exige, además de los

${ }^{32}$ E. Alarcos, op. cit.. p. 164, 219 y 220.

${ }^{33}$ Cfr. M. L. Hemánz -J. M. Brucart: La sintaxis (Barcelona: Crítica, 1987). p. 217.

${ }^{34}$ Coincidimos con el criterio de clasificación de H.A. Combé, «Some discrepancy phenomena in spanish», Bolkestein-Combé et allii, 1985 y de S. Gutiérrez, op. cit. 
actantes dativo y nominativo, este tipo de construcción a través del cual se orienta el oyente para su interpretación.

Su construcción verbal es la que hemos llamado SV heterogéneo ${ }^{35}$, pues a pesar de llevar dos formas verbales en la construcción de la oración, ésta mantiene un sólo significado.

\subsection{El modo en la subordinada sustantiva de PARECER}

La subordinada sustantiva de parecer se construye la mayoría de las veces en indicativo, como es el caso de los ejemplos seleccionados por nosotros, aunque no por ello deja de admitir el subjuntivo.

S. F. Ramírez ya dijo en cierta ocasión, que la subordinada sustantiva de parecer admite los dos modos, pero no con idéntico significado. «Cuando significa «parecer bien» exige siempre el subjuntivo, como en ¿Te parece que nos marchemos? El adverbio bien es optativo en tales situaciones ¿Te parece bien que hubiéramos pasado por cobardes? Contrastan, pues, claramente Me pareció que te marcharas con $M e$ pareció bien que te marcharas» ${ }^{36}$.

Sin embargo, debemos decir que este contraste de modo se debe a una diferencia sintáctica, pues cuando parecer se construye con una oración subordinada sustantiva cuya función es de atributo, el modo que aparece en ésta es el indicativo, mientras que cuando esta misma subordinada funciona de sujeto, ya que el adverbio bien (o uno cualquiera de estos elementos: mal, regular, oportuno, etc.) es ahora su atributo, el modo que presenta la subordinada es el subjuntivo.

\subsubsection{Construcción del cuarto valor de PARECER: «tener o dar la impresión»}

Aunque parecer no lleve sus propios actantes por funcionar como verbo auxiliar, no quiere esto decir que dejemós de lado el tipo de construcción con el que se realiza en esta ocasión.

Así, parecer con el valor lexemático arriba mencionado, también se construye como verbo funcionalmente atributivo. Aquí nos encontramos con diferentes tipos de formas que presentan las siguientes estructuras:

${ }^{35}$ Vid. nota 27.

${ }^{36}$ S. Fernández Ramírez, Gramática española. 4. El verbo y la oración (Madrid: Arco/libros, 1986), p. 319. Volumen ordenado y completado por I. Bosque. 


$$
\begin{aligned}
& \text { SN1 + V + Inf. } \\
& \text { V + que + Or. } \\
& \text { V + que + como si + Or. } \\
& \text { V + como que + Or. }
\end{aligned}
$$

Ejemplos textuales:

/6/a. Juan parecía conocer los procedimientos.

/6/b. Parece que Antonio no está enterado del asunto.

/6/c. Parecía como si alguien hubiera llamado a la puerta.

/6/d. Parecía como que todo se había acabado.

El ejemplo /6/a. es el resultado de la transformación de la siguiente oración:

7/ Parecía que Juan conocía los procedimientos.

El sujeto funcional Juan en /6/a. concuerda también con parecer, pues cuando la oración subordinada sustantiva es sustituida por otra de infinitivo, el sujeto de la subordinada es el mismo para las dos formas verbales. Así, en este caso, parecer ya no se comporta como verbo impersonal, puesto que Juan es ahora su sujeto.

Desde un punto de vista semántico las relaciones de /6/a. y /7/ se mantienen idénticas. En la oración Parecía que Juan conocía los procedimientos las relaciones clasémicas se establecen entre Juan (sujeto) y conocía (su núcleo predicativo).

En /6/a. tal relación sigue estableciéndose entre Juan y conocer, a pesar de que el sustantivo Juan es ahora sujeto de parecer. Este último tipo de construcción funciona también de atributo de parecer. Su conmutación por el átono pronominal lo y el adverbio asi es correcta. Por ejemplo:

/6/a. Juan parecía conocer los procedimientos... lo parecía / así parecía.

En los tipos de empleos ilustrados en /6/a., /6/b. y /6/c., parecer toma de nuevo el rasgo impersonal que lo caracteriza, y se construye mediante una subordinada sustantiva como la /6/b. o por medio de oraciones modales como la /6/c. y /6/d.

Todas estas subordinadas modales -incluyendo además la de infinitivo, pueșto que también puede ser conmutable por la expresión adverbial como si le dan un carácter modal a la oración. Todas ellas funcionan de atributo de parecer y la presencia del como aporta la idea de modo a la caracterización del atributo.

J. Martínez señala que los elementos indicadores de modalidad equivalen funcionalmente a aditamentos, y los denomina, entre otros, aditamento atributivo ${ }^{37}$.

Para tomar el valor que ahora consideramos, parecer necesita además construirse con un SV heterogéneo, pues, como ya se ha dicho en otras ocasiones, aunque las oraciones expuestas lleven dos formas verbales, éstas presentan un contenido propio.

${ }^{37}$ J. Martínez: «Sobre algunas estructuras atributivas», Lecciones del I y II Curso de lingüística funcional (Universidad de Oviedo, 1983-1984), pp. 111-119. 


\section{Uso discursivo del verbo PARECER en el Habla Urbana Culta de Sevilla}

En el capítulo anterior hemos estudiado, pues, las posibilidades virtuales que del verbo parecer ofrece la dinámica interna del sistema de la lengua española. Esta visión la contemplaremos, ahora, en simultaneidad, «con la atención investigadora al comportamiento actualizado que considera los hechos de actualización concreta, hechos ocasionales que se plasman en el enunciado discursivo como resultado específico de una de las posibles investigaciones» ${ }^{38}$.

Así, en este y en el siguiente capítulo, estudiaremos con más detalle el problema de las «situaciones sociolinguiísticas» con las observaciones de las posibilidades virtuales seleccionadas por los 24 informantes en su comportamiento de empleo discursivo; pues la actividad sociolingüística actúa a la vez tanto en los mecanismos de producción como en el comportamiento actualizado dentro de las posibilidades que ofrece el sistema. «El sistema de opciones disponibles es la gramática de la lengua, y el hablante o el escritor hace sus elecciones dentro de este sistema: no in vacuo, sino en el contexto de las situaciones del habla» ${ }^{39}$.

Por ello, una vez realizada la parte más teórica de nuestro trabajo, vamos a analizar a continuación, el comportamiento discursivo de parecer que de él hace el usuario culto de la ciudad de Sevilla ${ }^{40}$. Nos basaremos en la comparación y contraste del módulo de posibilidades con las ocurrencias documentadas en las encuestas ${ }^{41}$.

Para dar una idea más adecuada de cómo se reparten éstas por generación y por sexo, presentamos el siguiente cuadro:

${ }^{38}$ V. Lamiquiz, «Sobre la actividad comunicativa del discurso lingüístico», Lecciones del I y II. Curso de lingüística funcional, op. cit. p. 89.

${ }^{39}$ M. A. K. Halliday «Estructura y función del lenguaje», Nuevos horizontes de la lingüística. Introducción y selección de J. Lyons (Madrid Alianza, 1975), p. 147.

${ }^{40}$ Como bien especifica A. Narbona la norma culta «no es más que un ideal, que no debe identificarse del todo con la manera de expresarse de ningún grupo o ámbito en particular, no se trata de un «corsé» impuesto, sino de una aspiración de dominar la forma más eficaz y adecuada que garantice al máximo la comunicación entre los hablantes de una comunidad idiomática». A. Narbona, «Problemas de sintaxis coloquial andaluza», R.E.L., 16, 2 (1986), p. 236.

${ }^{41}$ El comportamiento discursivo de la unidad parecer lo hemos observado en el corpus seleccionado (24 encuestas grabadas e informatizadas) donde quedan diferenciadas las variables generación y sexo. (V. varones y $\mathrm{H}$. mujeres). La primera generación la componen individuos cultos cuyas edades están comprendidas entre los 21 y 29 años. La segunda generación entre los 30 y 45 años, y la tercera a partir de los 46 años. Por cada generación se eligen ocho encuestas, donde se contrasta el sexo de los informantes: hombres y mujeres. Cuatro encuestas, donde se contrasta el sexo de los informantes: hombres y mujeres. Cuatro encuestas de hombres y cuatro de mujeres. El informante es de Sevilla capital y a ser posible de familia arraigada en lo sevillano. Para mayor información cfr. R. Guillén, El Habla Culta de Sevilla. Estudio léxico (Sevilla: Alfar-Universidad, 1987). 


\subsection{Ocurrencias documentadas de verbo PARECER}

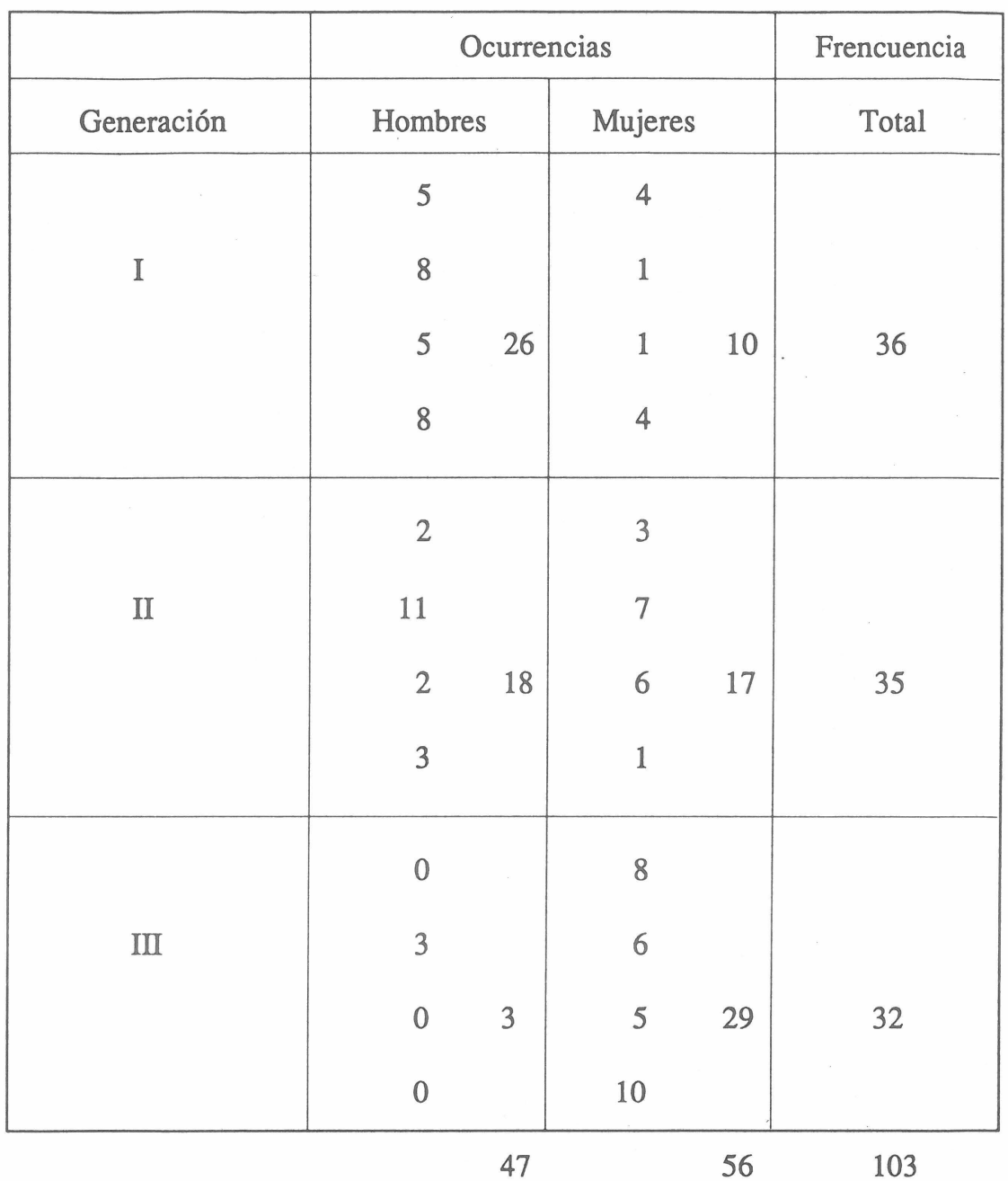

El cuadro recoge, pues, el número de ocurrencias correspondientes a dicha unidad, repartidas por generación y sexo.

La primera columna establece las diferentes ocurrencias que se dan entre los hombres de las tres generaciones; en la segunda columna aparecen las correspondientes a los informantes de sexo femenino, y en la tercera el recuento total del fenómeno.

Se observa que de las 103 ocurrencias que constituye el número total de la unidad parecer, 36 pertenecen a la primera generación, 35 a la segunda y 32 a la tercera, siendo las mujeres quienes hacen más uso de él que los hombres, pues 56 corresponden a ellas y 47 a ellos. 
Si se observa detenidamente cada uno de los resultados numéricos expuestos en el cuadro, comprobaremos la existencia de un progresivo descenso en el número de ocurrencias desde la primera generación a la tercera.

Una vez realizada la distribución del fenómeno por generación y sexo, pasamos enseguida a la elaboración del módulo discursivo del verbo que estudiamos, en el HUCS $^{42}$. Este módulo ha sido confeccionado a partir de los datos obtenidos en el corpus.

\subsection{Módulo discursivo de la unidad PARECER}

\begin{tabular}{|c|c|c|c|c|}
\hline LEXEMÁTICA & SINTAXIS & \multicolumn{2}{|c|}{ CONSTRUCCIÓN } & EJEMPLOS \\
\hline Alterna con & Actantes & Sintagma & Tipo & \\
\hline Aparentar & Nominativo ( \pm animado) & \multirow[b]{2}{*}{$\begin{array}{l}\text { Verbal } \\
\text { Homogéneo }\end{array}$} & Atributivo & 1) \\
\hline Asemejarse & Doble Nominativo (+ animado) & & $\begin{array}{l}\text { Pronominal } \\
\text { recíproco }\end{array}$ & 2) \\
\hline $\begin{array}{l}\text { Creer } \\
\text { Pensar } \\
\text { Opinar } \\
\text { Figurarse }\end{array}$ & $\begin{array}{l}\text { Nominativo (- animado) } \\
\text { Dativo (+ animado) }\end{array}$ & \multirow{3}{*}{$\begin{array}{c}\text { Verbal } \\
\text { Heterogéneo }\end{array}$} & $\begin{array}{l}\text { Atributivo } \\
\text { nexo que + Orac. }\end{array}$ & $\begin{array}{l}3 a) \\
3 b) \\
\text { 3c) } \\
4)\end{array}$ \\
\hline \multirow[t]{2}{*}{$\begin{array}{l}\text { Tener o dar } \\
\text { la impresión }\end{array}$} & \multirow[t]{2}{*}{ Los del verbo Predicativo } & & $\begin{array}{l}\text { Infinitivo } \\
\text { (mismo sujeto) }\end{array}$ & 5a) \\
\hline & & & $\begin{array}{c}\text { Como que } \\
\text { que + Oración }\end{array}$ & $\begin{array}{l}5 b) \\
5 c)\end{array}$ \\
\hline
\end{tabular}

${ }^{42}$ Las siglas corresponden a Habla Urbana Culta de Sevilla. 


\section{Valores sémicos de PARECER en el discurso ${ }^{43}$}

/1/ «De ahí el hecho este que se dice que puede parecer tópico, pero quizás cierto: que el turista es el que descubre al sevillano las cosas que tiene en realidad de bonitas desde el punto de vista artístico» $(\mathrm{C} 1 \mathrm{~V} 2,18)^{44}$.

/2/ «Yo me acuerdo que en una conferencia del Ateneo, decían que Sevilla estaba poco más o menos que parecía las estribaciones del Kenia, ¿no?» (C2V2, 115).

13/a. «(...), decía que el cazador cuando sale al campo después de levantarse la veda parece que va estrenando el mundo». (C2V4, 148).

$13 / \mathrm{b}$. «O sea, que hay algo oculto que, aunque parezca que no es propiamente una manifestación religiosa, hay gran parte de religioso en ello». (C3H3, 281).

/3/c. «La Macarena, también, me encanta también, pero me parece que ya tiene su fama y que le gusta a demasiada gente». (C2V2, 122).

/4/ «Me parece que tenía yo... Yo nací el veintinueve, tenía yo treintaiún años». (C2V1, 110).

15/a. «Ahora, pues, parece ser que esto está transformándose mucho con las reuniones de padres de tal y de cual». $(\mathrm{C} 2 \mathrm{H} 2,177)$.

15/b. «Ibamos a salir a pasar las vacaciones en otros lugares de España, tenía de siempre una emoción especial en el momento cuando volvíamos de las vacaciones y ya nos encontrábamos cerca, en la entrada de la ciudad, parecía que llegaba algo, algo mío que se había perdido». (C1V2, 17).

15/c. «Qué cuando saqué el título parecía que no servía para nada, porque pagaban $\tan$ mal que en realidad, me traía más cuenta trabajar en las cosas que yo podía». $(\mathrm{C} 2 \mathrm{~V} 2,115)$.

\subsubsection{Explicación del módulo discursivo de la unidad PARECER}

En él recogemos, pues, el empleo discursivo que los hablanes de un estrato culto de la ciudad de Sevilla, hacen de esta unidad.

En la zona lexemática del módulo que ahora nos ocupa, observamos que sólo está ausente el valor correspondiente a la tercera casilla del módulo ideal. Nos

${ }^{43}$ Partimos de unas 60.000 palabras textuales en las que se incluyen exactamente 103 ocurrencias relativas a este verbo de las cuales exponemos aquí un modelo discursivo de cada valor sémico.

${ }^{44}$ Las referencias que se dan entre paréntesis al final de cada ejemplo, indican: $\mathrm{C}$, nivel culto, la cifra siguiente señala la generación, y la letra que ocupa el tercer lugar, $\mathrm{V}$ o $\mathrm{H}$ indica el sexo: V (hombres) H (mujeres). 
referimos al caso concreto de «reprochar». La ausencia de este valor en el uso discursivo, se debe, en parte, al tema de las encuestas, ya que éste es bastante regular, pues a cada encuestado se les pide que hable de Sevilla, su profesión, aficiones o viajes realizados. Por ello, es poco probable que dichos informantes usen el verbo parecer con el valor antes mencionado, ya que no viene a menos a las preguntas que les hace el encuestador.

En los valores que se actualizan, se cumplen todos los requisitos paradigmáticos y sintagmáticos señalados en el modelo teórico (vid. módulo teórico). Es decir, se dan todos los condicionamientos lexemáticos-sintácticos que cada uno de los rasgos sémicos requiere; pues, como dice A. Alonso, «en la variedad de significaciones (o acepciones) cada una es la resultante de la confusión de las leyes de la forma con las leyes de la materia. La diferente materia es la que orienta la significación hacia la acción o hacia el estado, repetidos o singulares, hacia la caracterización psíquica o física» ${ }^{45}$. Esto quiere decir -aplicando la cita a nuestro lenguaje- que a cada valor lexemático le corresponde una determinada construcción sintáctica y viceversa.

Aparte de la coincidencia sintáctico -lexemática del módulo ideal con el de uso, nos parece interesante señalar que no en todos los empleos discursivos que se documentan, funciona parecer como verbo pleno, sino que tiene básicamente una función de adjetivo, como en:

/1/ «Y además el italiano es bastante parecido a nosotros». (C1H4, 97).

12/. «Algo parecido a lo que ocurre en el Hospital del Pozo Santo».

13/. «(Los de Madrid)... Hombre tienen un carácter parecido al nuestro». (C3H4, 291).

Los ejemplos /1/ y /3/ están relacionados significativamente con el valor que se encuentra en la acepción dos del módulo teórico: «asemejarse». El ejemplo /2/, no se encuentra registrado en ninguna acepción de este módulo, pues su significado es equivalente a los adjetivos semejante, igual, etc. Por tanto, en estos casos, parecer no funciona como verdadero funtor de predicación que exija unos actantes y una construcción determinada, por lo que este valor significativo no se ha incluido en el módulo de uso.

Se ha registrado además una serie de formas de parecer donde tampoco funciona como verbo pleno, sino que en la oración en la que aparece ha pasado a la lengua como frase hecha o como una simple expresión. Por ejemplo:

«También no se puede negar que en cuanto a la ciudad, desde el punto de vista se puede decir tópico, artístico, tiene muchas cosas que ver, pero puede ser, parecer ser, como el que se encuentra aquí en Sevilla, es decir, el que ha nacido en ella es el que menos, no, no se puede decir admira, pero es el que menos toma en cuenta». $(\mathrm{C} 2 \mathrm{~V} 2,18)$.

${ }^{45}$ A. Alonso, «Análisis de los contenidos», Estudios lingüísticos. Temas españoles (Madrid, Gredos, 1967), p. 222. 
«Generalmente parece ser, parece ser que sí, sí» $(\mathrm{C} 3 \mathrm{H} 1,254)$

Por otra parte, es muy normal que en situación de diálogo se den casos de elipsis gramaticales y sintácticas en la oración, lo cual no impide que se pierda el significado de la misma, ni tampoco se modifica la comprensión que ella conlleva, pues la elipsis, como dice J.M.H. Terre, es un fenómeno de ausencia de elementos que no ofrece dificultades interpretativas del significado global de la oración ${ }^{46}$. Por ejemplo:

«Y por eso te digo que yo creo que eso tiene que durar una semana me parece eh? Una semana». (C1V3, 34).

donde el informante mediante la forma me parece, repite lo anterior (que tiene que durar), ya que no hace falta formular de nuevo la oración subordinada sustantiva, pues el encuestado da por sabido que el encuestador, por el entorno lingüístico, lo comprende perfectamente, aunque cambie la forma del verbo: parecer por creer, pues tanto uno como otro expresan opinión.

\section{Estadística de uso}

En el apartado 3.1. se expone un cuadro donde se refleja la distribución de las ocurrencias de parecer por generación y sexo. A continuación, vamos a presentar un gráfico en el que se señala cómo se reparten proporcionalmente dichas ocurrencias entre los hablantes cultos de la ciudad de Sevilla:

\section{Gráfica de uso}

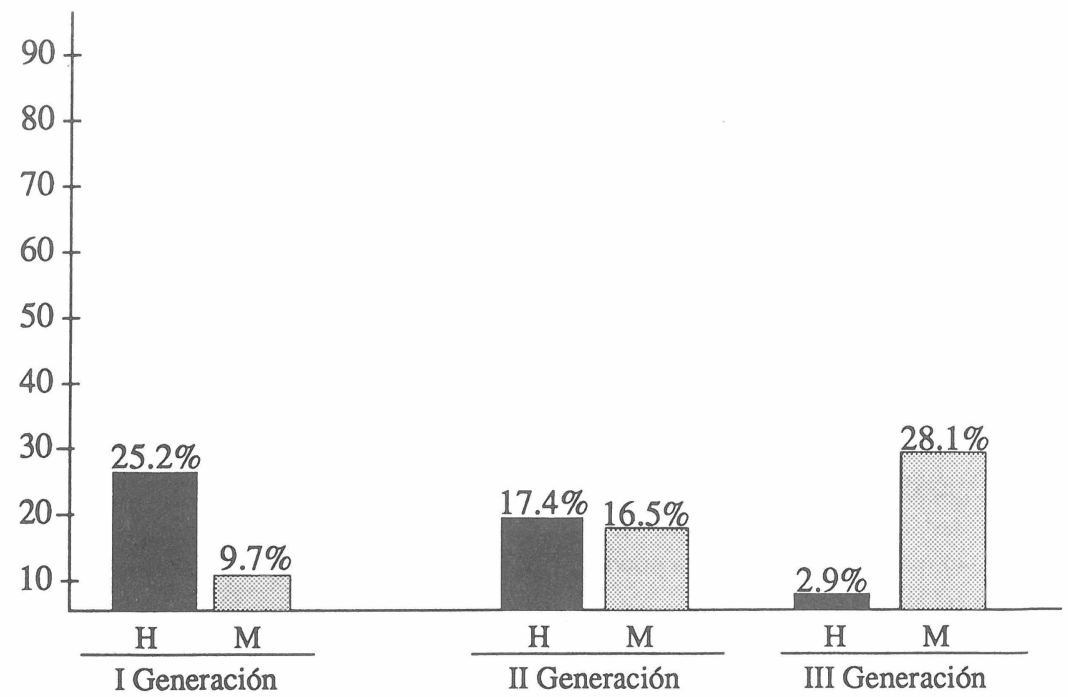

${ }^{46}$ J. M. H. Terre, La elipsis en la teoría gramatical (Murcia: P. Univers. de Murcia, 1984), p. 138. 
El porcentaje distribucional por generaciones no es altamente significativo, pues casi todos los datos numéricos están, en general, muy cercanos. En éstos existe un progresivo descenso desde la primera generación (34.9\%), pasando por la segunda (33.9\%) hasta llegar a la tercera (30\%).

En el resultado del desglose, según el sexo, se observa, curiosamente, que el verbo parecer es más aceptado por las mujeres de la tercera generación, las cuales manifiestan en el gráfico un mayor índice de aceptabilidad que los otros usuarios. Estas lo emplean en el $28 \%$ de las ocurrencias. Los hombres de la primera generación lo hacen en el $25.2 \%$, diferenciándose así de las mujeres de la misma edad que lo usan en el 9.7\%. Sin embargo, el porcentaje distribucional de los hombres y de las mujeres de la segunda generación no es significativo, puesto que prácticamente coinciden en el número: $17.4 \%$ (en las mujeres), frente a un $16.5 \%$ (en los hombres). El menor índice de aceptación lo tienen los hombres de más edad, pues aparece con un $2.9 \%$. La diferencia que puede haber, en cuanto al porcentaje estadístico, entre el sexo femenino (54.3\%) y el masculino (45.5\%), la señala los hombres de la tercera generación, debido, quizás, a que éstos en su expresión discursiva, apenas introducen la forma parecer en su léxico.

\section{Conclusión}

A lo largo de este trabajo nos hemos preocupado en mostrar las posibilidades lingüísticas de la unidad parecer en relación a sus sistema funcional idealizado con miras al estudio del comportamiento discursivo de ésta en el Habla Urbana culta de Sevilla.

Para estudiar al verbo en toda su operatividad, hemos tenido en cuenta una serie de rasgos esenciales:

- Lexemáticos (valores sémicos, alternancias).

- Sintácticos (predisposiciones actanciales).

- Constructivos (combinatorias de funciones).

De todo ello se ha comprobado que existe una estrecha interrelación entre los valores lexemáticos, sintácticos y de construcción. De manera que a un definido valor le corresponde una combinatoria de funciones determinadas que materializan las predisposiciones actanciales del funtor. Así, la unidad parecer actualiza ocho valores diferentes que dependen, por supuesto, de la combinatoria sintagmática con la que establece función. De esta combinatoria deducimos que parecer se comporta como verbo funcionalmente intransitivo y atributivo.

Conscientes de los criterios diversos que se han escrito acerca de la forma atributiva de parecer, optamos por decir que cuando funciona como tal puede llevar de atributo, además de la clásica categoría de adjetivo, un sustantivo o un segmento nominal introducido por el transpositor que, o incluso la forma de un infinitivo, ya que la valencia funcional de este verbo depende de que el atributo sea un adjetivo o un sustantivo, o que opte por el uno o por el otro. 
El esquema intransitivo sólo lo presenta con el valor de «asemejarse», pues, en esta ocasión, parecer, en la producción discursiva, selecciona a un único actante y sucede que el papel que desempeña éste es pasivo, por lo cual impide la existencia de un segundo participante.

Concluimos, pues, diciendo que pertenece a una consideración lingüística el reconocimiento de la «ductilidad sintáctica» de esta unidad verbal en cuanto que permite, en las zonas referidas, dobletes de construcción con variación en el número de actantes. Ahora bien, estas variables cobran sentido cuando son actualizadas en una frase textual. Así, el uso de un grupo de hablantes sevillanos ha subrayado la mayoria de las posibilidades lingüísticas dentro del funcionamiento sistémico. Es decir, casi todas las posibilidades virtuales que presentábamos en el módulo teórico de parecer, se encuentran actualizadas en el comportamiento discursivo del grupo sociolingüístico de sevillanos cultos. Destaca discursivamente el empleo abundante de parecer en la modalidad atributiva especialmente con el valor de «opinar» Y, de manera global, cabe decir, estadísticamente hablando, que la unidad parecer no presenta ningún rasgo sociolingüístico que sea sintomático, ya que los usuarios cultos sevillanos utilizan, a excepción de los hombres de más edad, de forma proporcional a este verbo. 